\title{
Radiological Assessment of Hip Fracture Union RUSH and Modified RUSH
}

\section{Xinlong Zhang}

Chengde Medical University Affiliated Hospital

\section{Wentao Ci}

Chengde Medical University Affiliated Hospital

Kaiwen Luo

Chengde Medical University Affiliated Hospital

Ziyang Xing

Chengde Medical University Affiliated Hospital shi yan ( $\square$ zhangxinlong125125@163.com )

Chengde Medical University Affiliated Hospital

Chenwei Guan

Chengde Medical University Affiliated Hospital

Qunfang Hu

Chengde Medical University Affiliated Hospital

Wutao Wu

Chengde Medical University Affiliated Hospital

Fan Yang

Chengde Medical University Affiliated Hospital

\section{Research Article}

Keywords: Intertrochanteric fracture, Fracture healing, Radiographic Union Score or Hip, Cortical bridging

Posted Date: November 12th, 2021

DOI: https://doi.org/10.21203/rs.3.rs-1059828/v1

License: (c) (i) This work is licensed under a Creative Commons Attribution 4.0 International License. Read Full License 


\section{Abstract}

Objective区lntertrochanteric fracture is a common senile disease, which is mainly treated by surgery. The evaluation of postoperative healing of such fractures has always been based on qualitative evaluation of clinical and radiological indicators. Currently, there are no quantitative evaluations of hip fracture union other than the Radiographic Union Score or Hip (RUSH) score. The aim of this study was to evaluate fracture healing of intertrochanteric fractures treated with intramedullary nailing and plates using RUSH and the modified RUSH score we developed.

Methods $\nabla W e$ collected a total of 96 patients with surgically treated intertrochanteric fractures, including 46 with lateral plate fixation and 50 with intramedullary nailing. Six orthopedic surgeons assessed the overall impression of fracture union on more than 200 postoperative X-rays without knowing any information, followed by the use of RUSH and modified RUSH to evaluate the x-rays separately to see if the two methods improved the consistency of intertrochanteric fracture union.

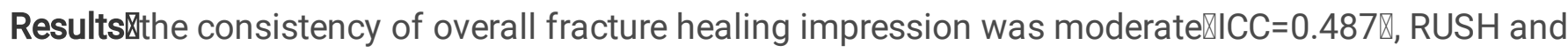

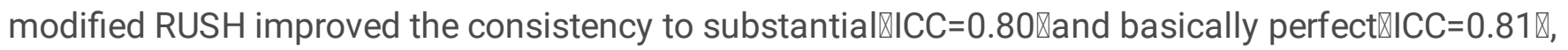
respectively. In addition, for the evaluation of union of all intertrochanteric fractures, the overall score of plate was always higher than that of intramedullary nail. When the lateral plate and intramedullary nail were separately scored, the RUSH score of plate was basically the same as modified RUSH, while the modified RUSH of intramedullary nail was higher than modified RUSH. Ultimately,the medial $(r=0.54$ and $R=0.53$ ) and anterior $(r=0.55$ and $R=0.54)$ and the global score $(R=0.68$ and $R=0.68)$ in the single cortex showed a high correlation with the overall fracture healing impression in both RUSH and modified RUSH scores. Ultimately,medial $(r=0.54$ and $r=0.53)$ and anterior $(r=0.55$ and $r=0.54)$ in individual cortices and overall scores $(r=0.68$ and $r=0.68)$ showed a high correlation with overall fracture healing impressions in both RUSH and modified RUSH scores.

Conclusions $\llbracket$ we developed a new hip fracture score comparable to the RUSH score that significantly improves the consistency of radiographic assessment of intertrochanteric fracture union. Most importantly, modified RUSH filled the callus formation gap in RUSH scores between cortical bridging and no cortical bridging. Therefore, we recommend the use of RUSH or a modified RUSH score to improve orthopedic surgeons' assessment of intertrochanteric fracture union.

\section{Introduction}

Hip fracture has always been a common clinical fracture disease,with the increase of aging population worldwide, the number of hip fracture is increasing year by year ${ }^{[1]}$.It is reported that intertrochanteric fracture accounts for about $50 \%$ of hip fractures in the elderly ${ }^{[2]}$. At present, Surgical treatment is the mainstream treatment method to reduce the mortality and disability rate of patients with intertrochanteric fracture.For the judgment of postoperative fracture union, radiological and clinical indicators are mostly used in clinic, including cortical callus or trabeculae bridge and completely painless weight-bearing respectively ${ }^{[3]}$. However, these evaluations of fracture union are qualitative and only can be simply classified as union or ununion. Such assessments are too subjective to be a good indicator of progress in fracture healing. In addition, due to 
the lack of consensus assessment, consistency among physicians in assessing fracture healing has been poor in the past.

In recent years, the emergence of Radiographic Union Scale for Tibia fractures(RSUT) score for evaluating tibia shaft has made a breakthrough in the quantitative direction of fracture healing evaluation ${ }^{[4]}$. The Radiographic Union Score for Hip(RUSH) was developed to a healing hip fracture after surgery based on tibial RUST score ${ }^{[5]}$, which mainly includes cortical bridging, cortical fracture line disappearance, trabecular consolidation and fracture line disappearance, with a total score of 10-30 points. Most previous studies have shown that RUSH scores are better predictors of hip fracture healing after surgery ${ }^{[6-8]}$, More crucial is that Bhandari found that the consistency between doctors evaluated hip fracture healing improved to a moderate level when RUSH was used ${ }^{[9]}$. Although the RUSH score is a better predictor of hip fracture healing progress, it still has drawbacks. In RUSH, cortical bridging is classified as no cortical bridging, partial cortical bridging, and complete cortical bridging.Nevertheless,the transition from callus absence to cortical bridging is a gradual process, it is not advisable that simply divide the process into no cortical bridging and partial cortical bridging. The same is true of for the disappearance of fracture lines. Once healing has begins, changes in RUSH scores occur only when there is substantial callus around the fracture until cortical bridging, which is clearly not friendly for assessing early postoperative fracture healing. Hence, in the callus formation stage of fracture union, cortical bridging and fracture line scores need to be more detailed in order to better evaluate hip fracture union. Currently, there are no other scores available to assess hip fracture union other than the RUSH score. The aims of these study were to assess the impression of postoperative Overall healing of intertrochanteric fractures treated with intramedullary nailing and plates, moreover, We proposed modified RUSH on the basis of RUSH score to compare the consistency between the two scores and verify the correlation between each cortex and overall fracture healing, aiming to improve the consistency and reliability among clinicians in evaluating postoperative intertrochanteric fracture healing.

\section{Methods}

A total of 96 patients with intertrochanteric fractures were treated surgically, including 50 with intramedullary nail (PFNA or Intertan) and 46 with lateral plates. All patients immediately underwent anteroposterior and lateral radiographs of the affected hip for the judges' reference after surgery, and each case had two or more postoperative radiographs of the hip at different stages, each with at least two images(Anteroposterior and lateral or axial radiographs). The x-rays were arranged in random order, with the name and date of each X-ray obscured, subsequently, the cases were referred to six orthopedic surgeons for evaluation. Physicians first determined whether the fracture was healing based on their own experience or past clinical and radiological assessment methods, second, performed RUSH and modified RUSH scores for each X-ray. This experiment has been approved by the Ethics Committee of the Affiliated Hospital of Chengde Medical College.

\section{Scoring:RUSH and Modifified RUSH}

The cases in this study were evaluated independently by each physician using two scoring methods. The scoring rules of the two methods will be introduced later. $\mathrm{RUSH}^{[5]}$ : the total score was $10-30$, including scores 
of cortical bridging, cortical fracture line disappearance, bone trabecular consolidation and bone trabecular fracture line. The total score for cortical bridging range from 4 to 12 , and the cortical condition was assessed from the medial, lateral, anterior and posterior directions respectively. Each cortical bridging was divided into no cortical bridging, partial cortical bridging and complete cortical bridging, with scores ranging from 1 to 3 points in order. The total score of cortical fracture line disappearance was consistent with that of cortical bridge, ranging from 4 to 12 points, which was scored on the basis of the visibility of the cortical fracture line in all four directions, with results was similar to that of cortical bridge. The two trabecular indices were assessed on the basis of trabecular consolidation and trabecular fracture line visibility, with scores ranging from 1 to 3 and the results were consistent. MModified RUSH: The total score range from 10 to 38 points and included a four-direction cortical assessment similar to the RUSH score, but unlike RUSH, with the modified RUSH, no cortical bridging was further subdivided to describe whether it was no callus or callus formation but no cortical bridging in order to more accurately describe radiographic healing progression. Obviously, each cortical score ranges from 1 to 4 , and each corresponding cortical fracture line is also scored from 1 to 4 depending on how visible the fracture line is. The two indices of trabecular bone were consistent with RUSH score. In addition, the orthopaedic surgeon's score for each location was recorded as the area with the least healing. In order to better explain the content and differences of the two scores, we selected two typical cases to describe the scores of each cortex and bone trabecula in detail, Fig.1, Table1, and Table2 demonstrate the postoperative healing of intertrochanteric fractures with lateral plate fixation, while Fig.2, Table 3, and Table 4 introduce the postoperative healing of intramedullary nail fixation.

\section{Statistical analysis}

$\square$ The intraclass correlation coefficient (ICC) coefficient of $95 \%$ confidence intervals was used to evaluate the overall fracture union.

口 ICC was used to evaluate RUSH and modified RUSH score to determine the degree of consistency between observers. ICC's assessment mainly refers to the criteria developed by Landis and Koch, including defined 0 0.20 as slight, $0.21-0.40$ as fair, $0.41-0.60$ is moderate, $0.61-0.80$ is substantial, and $>0.8$ is basically or absolute perfect. ICCs uses a two-way random model with absolute consistency in SPSS.

\ Finally, spearman correlation was used to evaluate the healing of each cortex (internal, lateral, anterior and posterior) and the overall fracture healing of RUSH and modified RUSH scores.

\section{Results}

The consistent of fracture healing impression between intramedullary nail and lateral plate fixation was fair $(I C C=0.384)$ and moderate, respectively, after $\mathrm{RUSH}(\mathrm{ICC}=0.732 \mathrm{ICC}=0.828)$ and modified $\mathrm{RUSH}(\mathrm{ICC}=0.757 \mathrm{I} \mathrm{ICC}=0.825)$, the consistency of intramedullary nails was substantial, and the lateral plates were almost perfect. posteriorly, the consistency of overall fracture healing impression was moderate खICC $=0.487 \rrbracket$, RUSH and modified RUSH improved the consistency to substantial $\mathbb{\text { ICC }}=0.80$ खand basically perfect $\rrbracket \mid \mathrm{CC}=0.81 \rrbracket$, respectively. 
For the evaluation of union of all intertrochanteric fractures, the overall score of plate was always higher than that of intramedullary nail. When the lateral plate and intramedullary nail were separately scored, the RUSH score of plate was basically the same as modified RUSH, while the modified RUSH of intramedullary nail was higher than modified RUSH.

For each component of RUSH and the modified RUSH score, we did a careful breakdown, evaluating each component separately. First, regardless of intramedullary nail or plate, in the evaluation of cortical bridging, cortical fracture line, trabecular fracture line and trabecular consolidation, the modified RUSH of cortical bridging and cortical fracture line was slightly higher than RUSH, and the consistency between intramedullary nail trabecular consolidation (ICC $=0.59)$ and fracture line $(I C C=0.60)$ was moderate, Lateral plate trabecular consolidation (ICC=0.69) and fracture line $(I C C=0.72)$ were substantial. For the four separate cortical Bridges and fracture lines, the consistency of RUSH and modified RUSH scores in medial, anterior and posterior cortex of the intramedullary nail and the plate was substantial. However, there was a great difference in the consistency of the lateral cortex between the two group. RUSH of the intramedullary nail was moderately consistent (ICC=0.58), while the plate was substantial (ICC=0.70). In the modified RUSH, the consistency of the intramedullary nail $(I C C=0.64)$ was improved, which reached substantial as the lateral plate, although there is still a certain gap with lateral plate $(\mathrm{ICC}=0.71)$.

\section{Correlation of each cortex (medial, lateral, anterior, posterior) with overall fracture healing impression}

In both RUSH and modified RUSH, medial $(r=0.54$ and $r=0.53)$ and anterior $(r=0.55$ and $r=0.54)$ in individual cortices and overall scores $(r=0.68$ and $r=0.68)$ showed a high correlation with overall fracture healing impressions.

\section{Discussion}

Currently, there is no unified standard for fracture healing among clinicians, and orthopedic surgeons mostly evaluate fracture healing by clinical and imaging indicators.Radiographs have always been the first choice of imaging because of their cheapness and convenience. However, the use of radiographs to evaluate fracture union has always been a problem of low consistency between observers ${ }^{[10]}$, To address this problem, Bhandari's RUSH score showed moderate consistency in orthopedic surgeons' assessment of hip fracture healing after surgery ${ }^{[9]}$. In addition, Litrenta designed a modified RUST score based on the RUST score used to evaluate distal femur fractures, which showed considerable consistency with the RUST score , more importantly, addressed the defects of the RUST score for the intermediate stage of fracture healing ${ }^{[4]}$. Unfortunately, this method is mainly used to evaluate cortical fractures such as tibia and femoral shaft, and is not applicable to hip fractures. Therefore, we developed the modified RUSH score based on the modified RUST and RUSH score in order to more accurately evaluate hip fracture healing. The content of this score is the same as that of RUSH's late score, including partial cortical bridge and complete cortical bridge. The only difference is that modified RUSH divides the early stage of fracture healing into two categories: no callus formation and callus but no cortical bridge, so as to fill the gap between cortical bridge and no cortical bridge 
in RUSH score. The aim is to obtain a wider range of scores during the critical healing period of callus formation to more accurately describe the progression of fracture healing. The key to the clinical application of RUSH and modified RUSH scores is the degree of consistency among clinicians. For all cases in the study, the results showed a substantial $(I C C=0.80)$ and almost perfect $(I C C=0.81)$ agreement between orthopedic surgeons who evaluated RUSH and modified RUSH, respectively. Therefore, both of these two scores can be applied to the evaluation of postoperative hip fracture healing, and the higher the score is, the higher the degree of fracture healing is.

In past studies, RUSH reported moderate consistency in the treatment of intertrochanteric fractures with intramedullary nailing. However, different internal fixation methods can lead to different callus formation. It has come to our knowledge that there has been no scoring system for intertrochanteric fractures treated with lateral plates. we hypothesized that RUSH and modified RUSH scores were also applicable to intertrochanteric fractures treated with lateral plates in order To illustrate their applicability. Litrenta of long bone fractures have demonstrated greater consistency with intramedullary fixation compared to plate fixation, whereas in our study of hip fractures, both RUSH and modified RUSH scores showed opposite results, with the lateral cortex score being the most significant difference. Others have indicated that lateral plates have less callus formation due to their rigid structure compared to intramedullary nailing ${ }^{[11,12]}$. Therefore, we believe that participating physicians are more likely to rate the lowest scores for early preoperative radiographs, Furthermore, for radiographs with cortical bridging already present, the raters tended to give the lateral cortex the highest score because the plate covered the lateral cortex, which appeared to be continuous whether or not the cortex was fully bridged. These was confirmed by our statistical results, which showed that $72 \%$ of the lateral cortices were rated lowest or highest in our lateral plate group, the highest proportion of all cortices.

We suggest that in the process of fracture healing, when multiple cortical callus are formed, it is more critical than the presence of bridged callus in one cortex, and its score should be higher correspondingly. nevertheless,in the early stage of fracture healing, when RUSH score was used to evaluate, the score of callus formation did not improve compared with that without callus formation, which significantly affected the

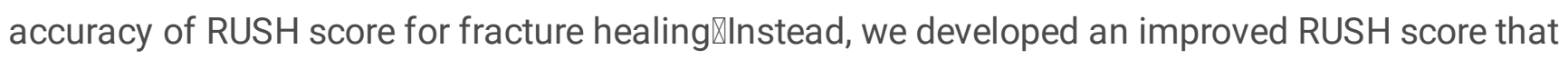
compensated for this shortcoming.

When intertrochanteric fractures occur, the medial femur cortex is usually destroyed, and its continuity is closely related to the stability and healing of intertrochanteric fractures. Previous studies have elaborated that when anteromedial femur cortex is damaged, fracture stability decreases and stress conduction is affected, resulting in delayed or poor bone healing ${ }^{[13,14]}$. Moreover, biomechanical researches have demonstrated that contact of the anteromedial cortex can spread the stress load of the implant and promote fracture healing by bringing the fracture site closer together ${ }^{[15]}$. The importance of good anteromedial cortical contact was particularly emphasized in Chang's new reduction quality criteria ${ }^{[16]}$, and Mao found by comparison that Chang's criteria emphasizing anteromedial cortical contact were more reliable than Baumgaertner's criteria in predicting mechanical complications including postoperative fracture nonunion ${ }^{[17]}$. Therefore, it is important to pay attention to the recovery of the anteromedial cortex after surgery. Our results strongly reflect that of the 
four cortices, the medial cortex was highly correlated with overall fracture healing impressions in both RUSH $(r=0.53)$ and modified RUSH ( $r=0.54)$, making both scores clinically useful.

Although modified RUSH is more suitable than RUSH for the early evaluation of fracture union, we do not emphasize the use of these two score to determine nonunion of hip fracture. inversely,we consider this score to be a good choice for evaluating fracture union when the progress of fracture union is unclear within a few months, in combination with clinical conditions and possible factors affecting nonunion.

Our study had several limitation. First of all, we encountered a large number of patients with insufficient follow-up times or lack of postoperative hip X-ray in two directions, which resulted in a not big sample size. Second, although the RUSH and modified RUSH scores of intertrochanteric fractures treated with lateral plates were higher than intramedullary nail, the results were bias due to inaccurate scores of the lateral cortex.

In conclusion, we developed a new hip fracture score comparable to the RUSH score that significantly improves the consistency of radiographic assessment of intertrochanteric fractures union. We recommend the use of RUSH or modified RUSH score to participate in the evaluation of intertrochanteric fracture union by orthopedic surgeons. We asked six orthopedic surgeons to evaluate these radiographs, in the future, we may invite more physicians or other specialists to participate in the evaluation to expand the applicability of RUSH and modified RUSH score for widespread clinical use.

\section{Abbreviations}

PFNA: Proximal femoral nail anti-rotating; RSUT:Radiographic Union Scale for Tibia fractures;RUSH:Radiographic Union Score for Hip; ICC:intraclass correlation coefficient

\section{Declarations}

\section{Acknowledgements}

Not applicable.

\section{Authors' contributions}

XLZ and SY conceived the study design, collected data, and participated in the study design.

WTC,CWG,QFH,FY,HTW, and KWL conducted X-ray scores.ZYX prepared the manuscript.XLZ and SY edited the manuscript.All authors read and approved the final manuscript.

\section{Funding}

There is no funding for this article. 


\section{Availability of data and materials}

We state that the data will not be shared since all the raw data are present in the figures included in the article.

\section{Ethics approval and consent to participate}

Not applicable.

\section{Consent for publication}

Not applicable.

\section{Competing interests}

The authors declare that they have no competing interests.

\section{References}

1. Mattisson Leif,Bojan Alicja,Enocson Anders,Epidemiology, treatment and mortality of trochanteric and subtrochanteric hip fractures: data from the Swedish fracture register.[J] .BMC Musculoskelet Disord, 2018, 19: 369.

2. Cheng Yan-Xiao,Sheng Xia,Optimal surgical methods to treat intertrochanteric fracture: a Bayesian network meta-analysis based on 36 randomized controlled trials.[J] .J Orthop Surg Res, 2020, 15: 402.

3. Dijkman Bernadette G,Sprague Sheila,Schemitsch Emil H et al. When is a fracture healed? Radiographic and clinical criteria revisited.[J] .J Orthop Trauma, 2010, null: S76-80.

4. Litrenta Jody,Tornetta Paul,Mehta Samir et al. Determination of Radiographic Healing: An Assessment of Consistency Using RUST and Modified RUST in Metadiaphyseal Fractures.[J] .J Orthop Trauma, 2015, 29: 516-20.

5. Bhandari Mohit,Chiavaras Mary,Ayeni Olufemi et al. Assessment of radiographic fracture healing in patients with operatively treated femoral neck fractures.[J] .J Orthop Trauma, 2013, 27: e213-9.

6. Frank Tym,Osterhoff Georg,Sprague Sheila et al. The Radiographic Union Score for Hip (RUSH) Identifies Radiographic Nonunion of Femoral Neck Fractures.[J] .Clin Orthop Relat Res, 2016, 474: 1396-404.

7. Bhandari Mohit,Chiavaras Mary M,Parasu Naveen et al. Radiographic union score for hip substantially improves agreement between surgeons and radiologists. [J] .BMC Musculoskelet Disord, 2013, 14: 70.

8. Bernaus Martí,Slobogean Gerard P,Bzovsky Sofia et al. Early Radiographic Union Score for Hip Is Predictive of Femoral Neck Fracture Complications Within 2 Years.[J] .J Orthop Trauma, 2020, 34: e195e202. 
9. Chiavaras Mary M,Bains Simrit,Choudur Hema et al. The Radiographic Union Score for Hip (RUSH): the use of a checklist to evaluate hip fracture healing improves agreement between radiologists and orthopedic surgeons.[J] .Skeletal Radiol, 2013, 42: 1079-88.

10. Atwan Yousif,Schemitsch Emil H,Radiographic evaluations: Which are most effective to follow fracture healing?[J] .Injury, 2020, null: S18-S22.

11. Henderson Christopher E,Lujan Trevor,Bottlang Michael et al. Stabilization of distal femur fractures with intramedullary nails and locking plates: differences in callus formation.[J] .lowa Orthop J, 2010, 30: 61-8.

12. Plumarom Yanin,Wilkinson Brandon G,Marsh J Lawrence et al. Radiographic Healing of Far Cortical Locking Constructs in Distal Femur Fractures: A Comparative Study With Standard Locking Plates.[J] .J Orthop Trauma, 2019, 33: 277-283.

13. Chen Shi-Yi,Chang Shi-Min,Tuladhar Rujan et al. A new fluoroscopic view for evaluation of anteromedial cortex reduction quality during cephalomedullary nailing for intertrochanteric femur fractures: the $30^{\circ}$ oblique tangential projection.[J] .BMC Musculoskelet Disord, 2020, 21: 719.

14. Li Jiantao,Zhang Licheng,Zhang Hao et al. Effect of reduction quality on post-operative outcomes in 31A2 intertrochanteric fractures following intramedullary fixation: a retrospective study based on computerised tomography findings.[J] .Int Orthop, 2019, 43: 1951-1959.

15. Park YC, Yoon SP, Yang KH. The effects of extramedullary reduction in unstable intertrochanteric fracture: a biomechanical study using cadaver bone. J Korean Fracture Soc. 2018;31(3):79-86.

16. Chang Shi-Min,Zhang Ying-Qi,Ma Zhuo et al. Fracture reduction with positive medial cortical support: a key element in stability reconstruction for the unstable pertrochanteric hip fractures.[J] .Arch Orthop Trauma Surg, 2015, 135: 811-8.

17. Mao Wei,Ni Haofei,Li Linli et al. Comparison of Baumgaertner and Chang reduction quality criteria for the assessment of trochanteric fractures.[J] .Bone Joint Res, 2019, 8: 502-508.

\section{Tables}

Table 1

RUSH 


\begin{tabular}{|llllll|}
\hline & $\begin{array}{l}\text { Medial } \\
\text { cortical }\end{array}$ & $\begin{array}{l}\text { Lateral } \\
\text { cortical }\end{array}$ & $\begin{array}{l}\text { anterior } \\
\text { cortical }\end{array}$ & $\begin{array}{l}\text { posterior } \\
\text { cortical }\end{array}$ & $\begin{array}{l}\text { Overall } \\
\text { Sorce }\end{array}$ \\
\hline no callus (Sorce=1) & $\square$ & $\square$ & $\square$ & $\square$ & 4 \\
\hline $\begin{array}{l}\text { Partial } \\
\begin{array}{l}\text { Cortical bridgings } \\
\text { (Sorce=2) }\end{array}\end{array}$ & & & & \\
\hline $\begin{array}{l}\text { Complete } \\
\text { cortical bridgings } \\
\text { (Sorce=3) }\end{array}$ & & & & & \\
$\begin{array}{l}\text { Overall sorce(range 4 to } \\
\text { 12) }\end{array}$ & 1 & 1 & 1 & 1 & 4 \\
\hline
\end{tabular}

\begin{tabular}{|c|c|c|c|c|c|}
\hline & Medial cortical & Lateral cortical & anterior cortical & posterior cortical & $\begin{array}{l}\text { Overal } \\
\text { Sorce }\end{array}$ \\
\hline $\begin{array}{l}\text { Fracture line } \\
\text { fully visible } \\
(\text { Sorce=1) }\end{array}$ & प & प & प & प & 4 \\
\hline $\begin{array}{l}\text { Some evidence of } \\
\text { Fracture line } \\
(\text { Sorce=2) }\end{array}$ & & & & & \\
\hline $\begin{array}{l}\text { Fracture line } \\
\text { disappearing } \\
(\text { Sorce=3) }\end{array}$ & & & & & \\
\hline $\begin{array}{l}\text { Overall sorce(range } \\
4 \text { to } 12 \text { ) }\end{array}$ & 1 & 1 & 1 & 1 & 4 \\
\hline
\end{tabular}




\begin{tabular}{|llll|}
\hline & $\begin{array}{l}\text { trabecular } \\
\text { consolidation }\end{array}$ & $\begin{array}{l}\text { trabecular } \\
\text { fracture line }\end{array}$ & $\begin{array}{l}\text { Overall } \\
\text { sorce }\end{array}$ \\
\hline $\begin{array}{l}\text { No consolidation/ Fracture line } \\
\text { fully visible (Sorce=1) }\end{array}$ & & 2 \\
\hline $\begin{array}{l}\text { Partial consolidation/some } \\
\text { evidence of the Fracture line (Sorce=3) }\end{array}$ & & \\
$\begin{array}{l}\text { Complete consolidation/Fracture } \\
\text { line disappearing=3 }\end{array}$ & & \\
\hline Overall sorce(range 2 to 6) & 1 & 1 & 2 \\
\hline
\end{tabular}

Table 2

Modified RUSH

\begin{tabular}{|c|c|c|c|c|c|}
\hline & $\begin{array}{l}\text { Medial } \\
\text { cortical }\end{array}$ & $\begin{array}{l}\text { Lateral } \\
\text { cortical }\end{array}$ & $\begin{array}{l}\text { anterior } \\
\text { cortical }\end{array}$ & $\begin{array}{l}\text { posterior } \\
\text { cortical }\end{array}$ & Sorce \\
\hline \multicolumn{6}{|l|}{ no callus (Sorce $=1$ ) } \\
\hline $\begin{array}{l}\text { callus formation } \\
(\text { Sorce }=2)\end{array}$ & प & प & प & प & 8 \\
\hline \multicolumn{6}{|l|}{ Partial } \\
\hline \multicolumn{6}{|l|}{$\begin{array}{l}\text { Cortical bridging } \\
\text { (Sorce=3) }\end{array}$} \\
\hline \multicolumn{6}{|l|}{$\begin{array}{l}\text { Complete } \\
\text { cortical bridging } \\
\text { (Sorce=4) }\end{array}$} \\
\hline $\begin{array}{l}\text { Overall sorce(range } 4 \text { to } \\
\text { 16) }\end{array}$ & 2 & 2 & 2 & 2 & 8 \\
\hline
\end{tabular}




\section{Medial cortical Lateral cortical anterior cortical posterior cortical Sorce}

Fracture line

fully visible(fracture

separation)

(Sorce=1)

Fracture line

口

口

प

प

mostly visible

(Sorce $=2$ )

Fracture line Blurred

(Sorce=3)

Fracture line

disappearing

(Sorce=4)

Overall sorce(range 2

4 to 16)

2

2

2

8

\begin{tabular}{|llll|}
\hline & $\begin{array}{l}\text { trabecular } \\
\text { consolidation }\end{array}$ & $\begin{array}{l}\text { trabecular } \\
\text { fracture line }\end{array}$ & $\begin{array}{l}\text { Overall } \\
\text { sorce }\end{array}$ \\
\hline $\begin{array}{l}\text { No consolidation/ Fracture line } \\
\text { fully visible (Sorce=1) }\end{array}$ & & 2 & 2 \\
\hline $\begin{array}{l}\text { Partial consolidation/some } \\
\text { evidence of the Fracture line (Sorce=2) }\end{array}$ & & \\
\hline $\begin{array}{l}\text { Complete consolidation/Fracture } \\
\text { line disappearing (Sorce=3) }\end{array}$ & & & \\
\hline Overall sorce(range 2 to 6) & 1 & 1 & 2 \\
\hline
\end{tabular}

Table 3

RUSH 


\begin{tabular}{|llllll|}
\hline & $\begin{array}{l}\text { Medial } \\
\text { cortical }\end{array}$ & $\begin{array}{l}\text { Lateral } \\
\text { cortical }\end{array}$ & $\begin{array}{l}\text { anterior } \\
\text { cortical }\end{array}$ & $\begin{array}{l}\text { posterior } \\
\text { cortical }\end{array}$ & $\begin{array}{l}\text { Overall } \\
\text { Sorce }\end{array}$ \\
\hline no callus (Sorce=1) & $\square$ & & & & 1 \\
\hline $\begin{array}{l}\text { Partial } \\
\begin{array}{l}\text { Cortical bridging } \\
\text { (Sorce=2) }\end{array}\end{array}$ & $\square$ & $\square$ & 6 & \\
\hline $\begin{array}{l}\text { Complete } \\
\text { cortical bridging } \\
\text { (Sorce=3) }\end{array}$ & & & & & \\
$\begin{array}{l}\text { Overall sorce(range 4 to } \\
\text { 12) }\end{array}$ & 1 & 2 & 2 & 2 & 7 \\
\hline
\end{tabular}

\begin{tabular}{|c|c|c|c|c|c|}
\hline & Medial cortical & Lateral cortical & anterior cortical & posterior cortical & $\begin{array}{l}\text { Overal } \\
\text { Sorce }\end{array}$ \\
\hline $\begin{array}{l}\text { Fracture line } \\
\text { fully visible } \\
(\text { Sorce=1) }\end{array}$ & प & & & & 1 \\
\hline $\begin{array}{l}\text { Some evidence of } \\
\text { Fracture line } \\
(\text { Sorce=2) }\end{array}$ & & $\square$ & $\square$ & प & 6 \\
\hline $\begin{array}{l}\text { Fracture line } \\
\text { disappearing } \\
(\text { Sorce=3) }\end{array}$ & & & & & \\
\hline $\begin{array}{l}\text { Overall sorce(range } \\
4 \text { to } 12 \text { ) }\end{array}$ & 1 & 2 & 2 & 2 & 7 \\
\hline
\end{tabular}




\begin{tabular}{|llll|}
\hline & $\begin{array}{l}\text { trabecular } \\
\text { consolidation }\end{array}$ & $\begin{array}{l}\text { trabecular } \\
\text { fracture line }\end{array}$ & $\begin{array}{l}\text { Overall } \\
\text { sorce }\end{array}$ \\
\hline $\begin{array}{l}\text { No consolidation/ Fracture line } \\
\text { fully visible (Sorce=1) }\end{array}$ & & \\
\hline $\begin{array}{l}\text { Partial consolidation/some } \\
\text { evidence of the Fracture line (Sorce=2) }\end{array}$ & & 4 \\
\hline $\begin{array}{l}\text { Complete consolidation/Fracture } \\
\text { line disappearing (Sorce=3) }\end{array}$ & & \\
\hline Overall sorce(range 2 to 6) & 2 & 2 & 4 \\
\hline
\end{tabular}

Table 4

Modified RUSH

\begin{tabular}{|c|c|c|c|c|c|}
\hline & Medial cortical & Lateral cortical & anterior cortical & posterior cortical & Sorce \\
\hline \multicolumn{6}{|l|}{ no callus (Sorce $=1$ ) } \\
\hline $\begin{array}{l}\text { callus } \\
\text { formation (Sorce=2) }\end{array}$ & प & & & & 2 \\
\hline Partial & & Q & प & प & 9 \\
\hline \multicolumn{6}{|l|}{$\begin{array}{l}\text { Cortical } \\
\text { bridging (Sorce=3) }\end{array}$} \\
\hline \multicolumn{6}{|l|}{$\begin{array}{l}\text { Complete } \\
\text { cortical } \\
\text { bridging (Sorce=4) }\end{array}$} \\
\hline $\begin{array}{l}\text { Overall sorce(range } \\
4 \text { to } 16 \text { ) }\end{array}$ & 2 & 3 & 3 & 3 & 11 \\
\hline
\end{tabular}




\section{Medial cortical Lateral cortical anterior cortical posterior cortical Sorce}

Fracture line

fully visible(fracture

separation)

(Sorce=1)

Fracture line

mostly visible

(Sorce=2)

Fracture line Blurred

(Sorce=3)

Fracture line

disappearing

(Sorce=4)

Overall

sorce(range 4 to 16 )
2

3

3
3

11

\begin{tabular}{|llll|}
\hline & $\begin{array}{l}\text { trabecular } \\
\text { consolidation }\end{array}$ & $\begin{array}{l}\text { trabecular } \\
\text { fracture line }\end{array}$ & $\begin{array}{l}\text { Overall } \\
\text { sorce }\end{array}$ \\
\hline $\begin{array}{l}\text { No consolidation/ Fracture line } \\
\text { fully visible (Sorce=1) }\end{array}$ & & \\
\hline $\begin{array}{l}\text { Partial consolidation/some } \\
\text { evidence of the Fracture line (Sorce=2) }\end{array}$ & & & \\
\hline $\begin{array}{l}\text { Complete consolidation/Fracture } \\
\text { line disappearing (Sorce=3) }\end{array}$ & & \\
\hline Overall sorce(range 2 to 6) & 2 & 2 & 4 \\
\hline
\end{tabular}

\section{Figures}




\section{Fig1:}
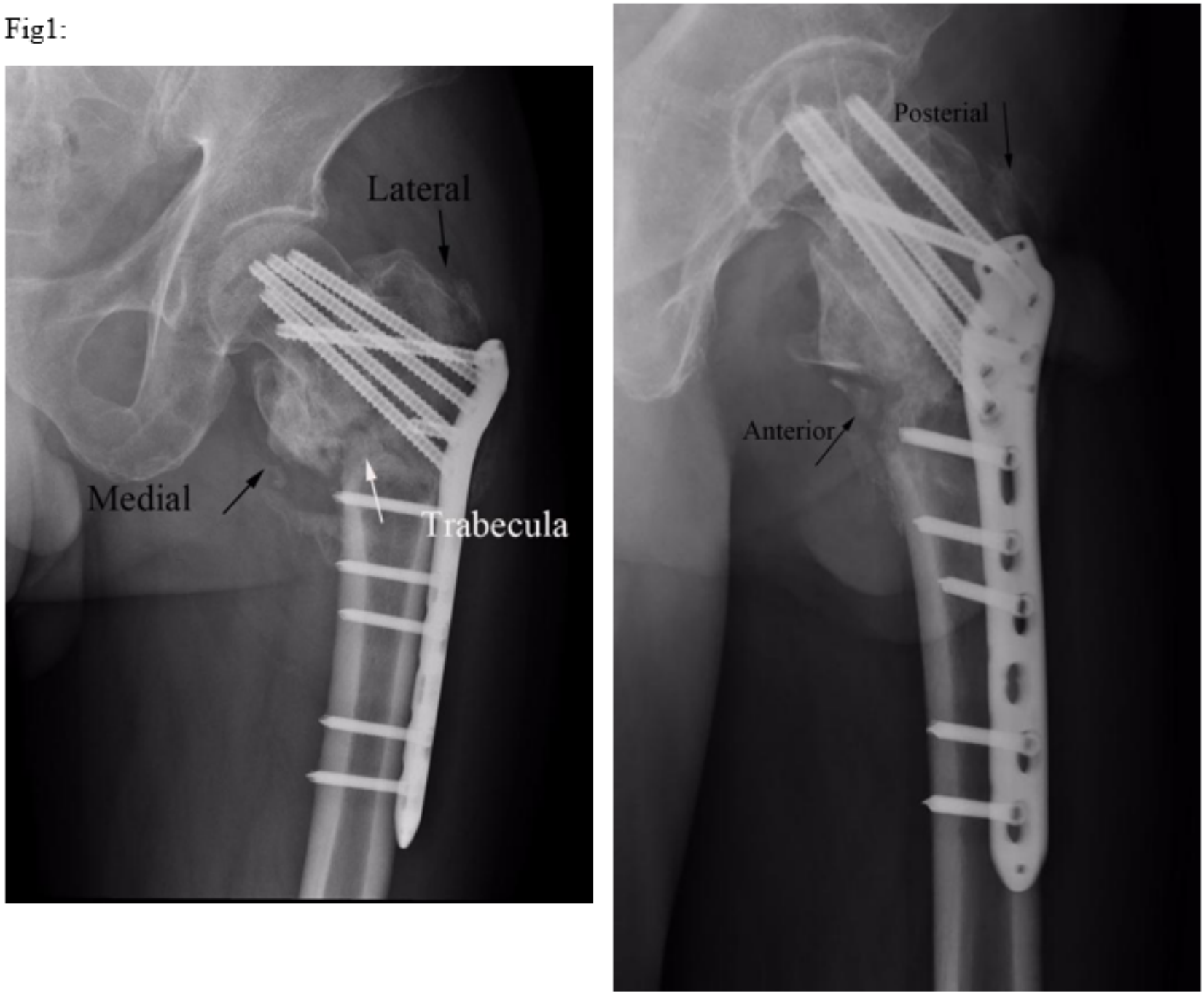

\section{Figure 1}

Fig.1, Table1, and Table2 demonstrate the postoperative healing of intertrochanteric fractures with lateral plate fixation 
Fig2:
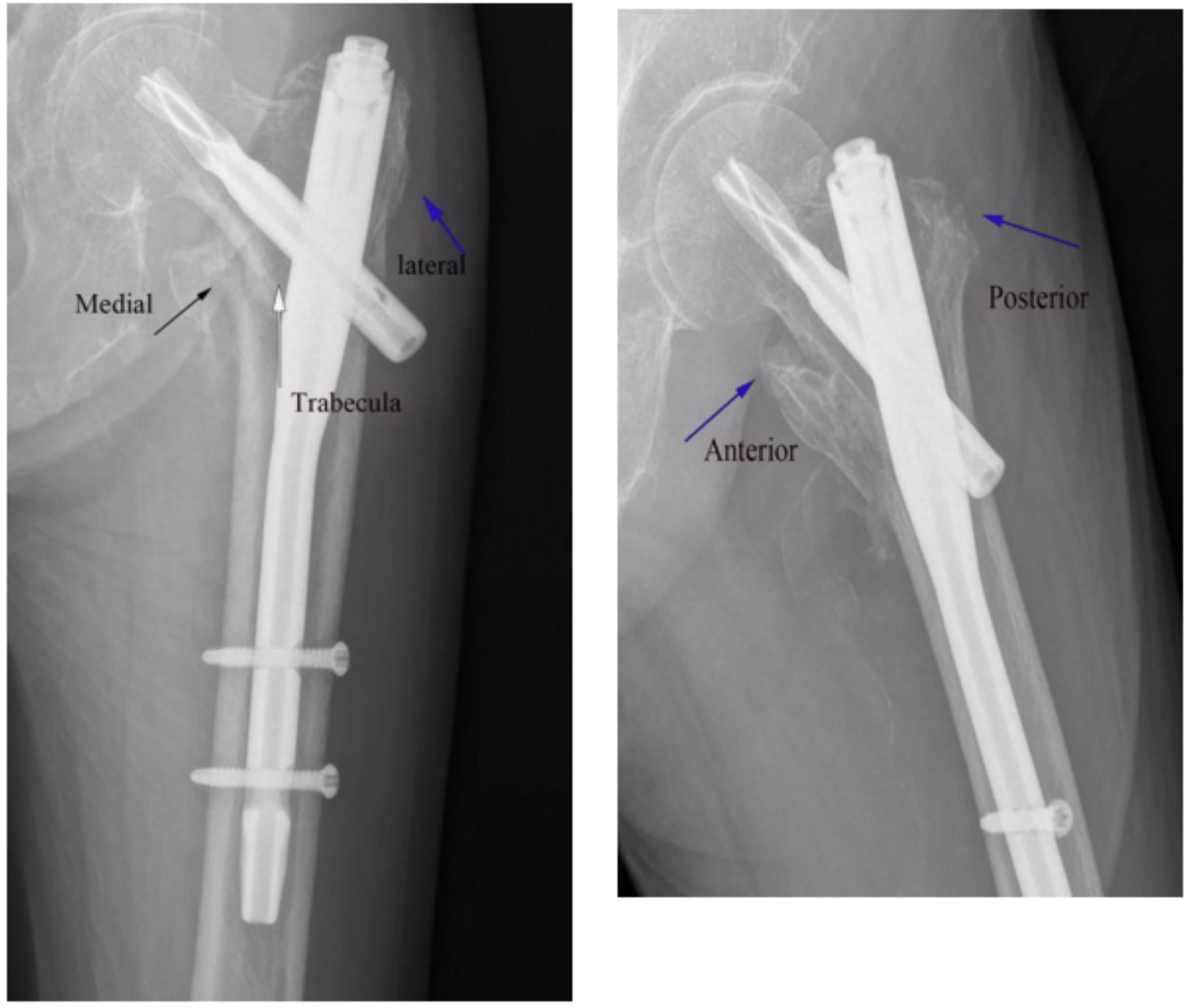

Figure 2

Fig.2, Table 3, and Table 4 introduce the postoperative healing of intramedullary nail fixation. 